\title{
Ecologia das relações espaciais: as preposições do crioulo guineense ${ }^{1}$
}

Hildo Honório do Couto

Universidade de Brasília (Brasil)

Elza Kioko N. N. do Couto

Universidade Federal de Goiás (Brasil)

\section{Introdução}

O tópico em questão faz parte de um contexto maior que é a questão das relações entre língua e meio ambiente (MA), no caso, meio o ambiente físico, o espaço. Essas relações vêm sendo estudadas desde pelo menos os gregos como, por exemplo, no conhecido diálogo de Platão, Crátilo, em que a personagem Crátilo defendia a tese de que as palavras refletem de alguma maneira as coisas a que se referem (thésis). A tese oposta (phýsis), de que as palavras são convencionais, era defendida por Hermógenes. Em 1912, Edward Sapir reconheceu alguma influência do MA no léxico, embora ele se mostrasse relutante em ver o mesmo efeito na gramática (in Mandelbaum 1949, p. 89-103).

Nos últimos tempos, a questão "língua e meio ambiente" tem sido abordada, mas apenas da perspectiva das relações entre língua e MA social. É o que fizeram Haugen (1972) e Fill (1993), entre outros. Outros tipos de MA da língua têm sido ou postos de lado ou mencionados apenas tangencialmente. Na verdade, a língua tem pelo menos quatro MA, além do social, todos eles no contexto do respectivo ecossistema. O primeiro, de caráter abrangente e integrador, é o MA Social da Língua, inserido no Ecossistema Fundamental da Língua. Do interior desse ecossistema, emergem três outros ecossistemas, em cada um dos quais a língua está relacionada ao respectivo MA. São eles o Ecossistema Social da Língua (no seio do qual ela tem seu MA Social), o Ecossistema Mental da Língua (em que ele se liga ao seu MA Mental) e o Ecossistema Natural da Língua (dentro dele ela se relaciona com o MA Natural). É sobretudo o último que será usado no estudo da ecologia das relações espaciais das preposições crioulo-guineenses. 
No que subsegue, teremos, na seção 1, um apanhado geral da nova disciplina ecolinguística, que é justamente a ciência das relações entre língua e meio ambiente em geral. Na seção 2, apresentaremos o Ecossistema Fundamental da Língua, com as seguintes subseções: 3.1 Ecossistema Social da Língua, 2.2 Ecossistema Mental da Língua e 2.3 Ecossistema Natural da Língua, com respectivos MA. Em 2.4, temos uma discussão sobre as inter-relações entre esses MA. A seção 3 é dedicada à Ecologia das Relações Espaciais, exemplificada com preposições portuguesas. $\mathrm{Na}$ seção 4, temos uma visão de conjunto das preposições crioulas, como preparação ao estudo das relações espaciais. A seção 5 enfoca a ecologia das relações espaciais nas preposições crioulas, conforme o modelo visto na seção 3. Na seção 6, tentamos analisar outras relações espaciais, não incluídas na seção 3, ou seja, preposições de movimento. A seção 7 dedica-se a preposições que aparentemente não são espaciais, tentando mostrar que elas são redutíveis à espacialidade. A seção 8 trata da questão de se há preposições espaciais que não se reduzem à espacialidade. Na seção 9, investigamos o que Bernard Pottier chama "uso nocional" das preposições. A seção 10 trata de alguns usos de preposições espaciais crioulas que nos parecem estranhos, embora o modelo apresentado na seção 3 nos permita perceber que não é o caso. Na seção 11, levantamos a questão de se o que se chama de "preposições complexas", é efetivamente complexo ou se deixa decompor em preposições simples, monoforfêmicas. Em 12, tentamos relacionar as relações espaciais examinadas nas seções precedentes ao MA físico da língua, uma vez que em geral se pensa que as preposições, como palavras funcionais que são, não teriam nada a ver com o mundo fora da língua. O capítulo termina com as considerações finais.

\section{Ecolinguística}

O conceito "ecolinguística" apareceu pela primeira vez em Salzinger (1979), embora Adam Makkai tenha nos dito que o ouvira de Einar Haugen em 1970. Em 1985, ele foi de novo sugerido, embora não desenvolvido em Hagège (1985). A ideia em si foi apresentada oralmente por Sapir em 1911, sob o título "Language and environment", perante a American Anthropological Association e, posteriormente, publicada no ano seguinte no American Anthropologist 14. Em 1972, saiu conhecido ensaio de Haugen mencionado acima. Daí para frente, saíram diversos outros ensaios, entre eles os de Mackey $(1979,1980)$. Esse desenvolvimento culminou com o aparecimento de Fill (1993) e Makkai (1993), sem que um soubesse do outro. O primeiro definiu a emergente disciplina da seguinte maneira: 
Einar Haugen, considerado o pai da ecolinguística, definiu o que chamou de "ecology of language" e "language ecology" como "o estudo das interações entre qualquer língua dada e seu meio ambiente" (Haugen, 1972, p. 325). Essa definição não é incompatível com a de Fill, uma vez que a última inclui a ideia de que ecolinguística "trata das inter-relações [...] entre língua e mundo". Partindo desses precursores, nós temos adotado a seguinte definição: Ecolinguística é a disciplina que trata das relações entre língua e meio ambiente. Mas, o que vem a ser MA da língua? A ecologia nos ensina que MA é parte de um ecossistema (Odum, 1971), de que é considerado seu ingrediente mais importante. O equivalente desse conceito nos estudos linguísticos é o todo formado pela população (P) e as inter-relações entre seus membros com o território (T). É o que veio a ser chamado Ecossistema Fundamental da Língua. Dentro dele, P e T constituem o MA maior da língua. Esse ecossistema maior, e respectivo MA, compreende três ecossistemas menores, e respectivos MA. Assim, temos o Ecossistema Social, Ecossistema Mental e o Ecossistema Natural da Língua, cada um com o respectivo meio ambiente. Vejamos cada um deles.

\section{O Ecossistema Integral da Língua}

Quando um leigo ouve o nome de uma língua (L) desconhecida, a primeira pergunta que lhe vem à mente é que povo $(\mathrm{P})$ a fala. Diante da resposta, ele pode querer saber também onde (T) vive esse povo. Essa tríade não é nada mais nada menos do que Ecossistema Integral da Língua (EIL), ou Comunidade, equivalente linguístico do ecossistema biológico. Na figura 1, vemo-lo representado graficamente.

Figura 01: Ecossistema Integral da Língua

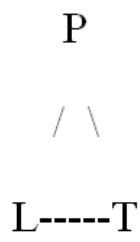

O EIL lembra o signo de Peirce: L equivale ao representante; P corresponde ao interpretante; T equivale ao referente (Peirce, 1972, p. 94). Na verdade, a linha entre P e T deveria ser segmentada, pois não há relação direta entre ambos, exatamente como não há relação direta entre representante e referente no signo peirceano. Com base em Albert Bandura, Wilhelm Trampe (1990) fala do "determinismo recíproco existente entre comportamento (L), população (P) e meio ambiente (T)". 
A totalidade dos indivíduos que formam $\mathrm{P}$, juntamente com suas interações reais e potenciais, constituem o MA Social da Língua. A totalidade constitui o Ecossistema Social da Língua. Na verdade, os membros de P juntamente com L constituem a sociedade. Mas, como disse Haugen (1972, p.325), "a língua só existe nas mentes de seus usuários". O cérebro/mente dos membros constitui Ecossistema Mental da Língua, no seio do qual as conexões neurais constituem o MA Mental da Língua. Finalmente, podemos considerar L em relação ao MA Natural, físico, que fica no interior do Ecossistema Natural da Língua. Tudo na dinâmica da língua tem a ver com esses três ecossistemas e respectivos MA.

Gostaríamos de acrescentar que há outros precursores do EFL, além dos recém-mencionados. Entre eles, poderíamos mencionar as "dimensões" de Døør \& Bang (1996, p. 23). O Ecossistema Social da Língua corresponde à "dimensão sócio-lógica" desses autores. O Ecossistema Mental da Língua equivale à "dimensão ideo-lógica" deles. Por fim, o Ecossistema Natural da Língua equivale à "dimensão "bio-lógica". Aparentemente, todas as propriedades do ecossistema biológico têm equivalentes nos ecossistemas linguísticos. Por exemplo, o primeiro não tem limites claramente definidos; eles são determinados pelo investigador, de modo que sempre há transições entre qualquer ecossistema e o próximo (Tansley, 1935). Pois bem, como os dialetólogos do final do século XIX já haviam notado, tampouco entre as línguas existem limites claramente definidos. Assim, na fronteira Brasil-Uruguai é difícil determinar-se onde termina o português e onde começa o espanhol. Uma exceção seria o Ecossistema Mental, uma vez que ele está contido no cérebro, cujos limites estão no interior da caixa craniana.

\subsection{O Ecossistema Social da Língua}

O Ecossistema Social da Língua é o mais conspícuo dos três. A tal ponto que Haugen (1972, p. 325) chegou a afirmar que "o verdadeiro meio ambiente da língua é a sociedade que o usa como um de seus códigos". Na verdade, a maioria dos ecolinguistas atuais seguem essa linha, como é o caso de Fill (1993), Mühlhäusler (2003), Calvet (1999), bem como da maioria dos colaboradores das antologias publicadas até hoje (cf. Fill \& Mühlhäusler 2001; Fill, Penz \& Trampe 2002). Os trabalhos que não tratam desse MA (social), em geral se dedicam a questões epistemológicas da disciplina. Com isso, não estamos menosprezando esses trabalhos, mas apenas salientando a tendência geral nos estudos ecolinguísticos. Queremos enfatizar também que há outros dois ecossistemas da língua, com respectivos MAs.

Um argumento a favor do Ecossistema Social da Língua é justamente sua conspicuidade; ele corresponde ao que o senso comum pensa de L. Tanto que 
se pudéssemos fazer um levantamento da orientação de todos os linguistas do mundo, talvez uns $60 \%$ deles abordassem a língua da perspectiva social. Teorias mentalistas como a da gramática gerativa são mais escassas. Toda teoria linguística que parte da interação vê na língua um fenômeno social. Como disseram Døør \& Bang (1996, p. 23-24), "sem práxis social não haveria língua natural nem signo linguístico nem texto. Uma língua natural é um meio cultural que estiliza e formaliza modos de interação social". Mesmo considerada em relação ao cérebro, de algum modo L tem a ver com o social. Na verdade, são as interações sociais dos membros de P entre si e com o MA que fazem L se estabelecer na mente.

Entre os assuntos que têm sido estudados sob essa rubrica, poderíamos mencionar o discurso ambiental, o discurso dos poluidores que querem passar-se por ambientalmente corretos, $\mathrm{o}$ antropocentrismo, o etnocentrismo, $\mathrm{o}$ androcentrismo (machismo), bem como as ideias de desenvolvimento e o correlato de grandeza, de acordo com o qual o bom é crescer, tornar-se "grande". Nas sociedades ocidentais, não é bom ser pequeno, é preciso "desenvolver", a qualquer custo (para o MA). Mas, os ecolinguistas dessa orientação defendem também a diversidade linguística (linguodiversidade), juntamente com a diversidade biológica (biodiversidade). É o caso das línguas minoritárias, dos dialetos e de outras variedades linguísticas. Enfim, eles defendem a diversidade, no sentido mais amplo do termo. Como está implícito em Haugen, os assuntos tradicionalmente tratados nesse contexto antes da emergência da ecolinguística são objeto da sociolinguística, tais como o multilinguismo (que inclui o bilinguismo), a variação linguística e o contato de línguas. Os estados que têm muitas línguas em seu território precisam decidir (e impor) uma língua estatal ou oficial. Isso é um dos tópicos do planejamento linguístico, ao qual o próprio Haugen dedicou vários estudos. Experiências individuais que ficassem restritas ao indivíduo, ou seja, que não fossem compartilhadas com outros indivíduos da comunidade, desapareceriam. Individualmente, elas poderiam até persistir por muitos anos, mas não seriam fenômenos de L. Tanto que, assim que o indivíduo morre, essas experiências morrem com ele.

\subsection{O Ecossistema Mental da Língua}

O Ecossistema Mental da Língua é o cérebro e a mente. O cérebro, ou sistema nervoso central, é dividido em dois hemisférios, e está ligado ao sistema nervoso periférico, que conecta o indivíduo com o mundo externo. Chega a ser irônico o fato de que o ecossistema da língua mais delimitado é um dos menos conhecidos. Há razões para isso, ou seja, por estar dentro do crânio, tem sido difícil estudá-lo sem lesões sérias. No entanto, nos últimos anos, Pierre Broca (1824-1880) e Carl Wernicke (1848-1905) fizeram descobertas de alta relevância. Broca chegou à conclusão 
de que o hemisfério esquerdo é dominante no processamento da linguagem, o que veio a ser chamado de lateralização. Wernicke, por seu turno, descobriu que as imagens sonoras localizam-se no lóbulo temporal esquerdo, posterior ao córtex auditivo primário. O que é mais, com o advento de técnicas não-invasivas como positron emission tomography (PET) e functional magnetic resonance imaging (FMRI), abriu-se o caminho para investigações mais detalhadas sobre as relações entre língua e cérebro.

De acordo com Sydney M. Lamb (2005), nosso sistema de informação é "implementado basicamente no córtex cerebral, associado com matéria que provê conexões córtico-corticais". Estas "incluem o sistema linguístico juntamente com os sistemas conceptual, perceptual e outros" (Lamb, 2000, p. 5). Desse modo, as palavras estão representadas como nós em que diversas relações se interconectam. Nesse caso,

\begin{abstract}
o nó para uma categoria conceptual parece ter conexões para/de um grande número de nós que representam suas propriedades. Por exemplo, conceitos para categorias de objetos visíveis precisam de conexões para nós da área visual, conceitos para objetos auditivos para/de nós auditivos e assim por diante. Tomando-se o conceito Cgato, por exemplo, temos conexões visuais relativas à aparência dos gatos, conexões auditivas para o "miau" e outros sons feitos pelos gatos, conexões táteis para o que se sente no contato com eles. Além disso, há conexões para outros conceitos que representam informações sobre os gatos no sistema de informação da pessoa em cujos sistemas essas conexões se formaram (Lamb, 2000, p.6).
\end{abstract}

Quando ouvimos a palavra "banana", por exemplo, a imagem de banana e dos sons que a compõem são ativados imediatamente (ativação máxima). Mas, outros conceitos e sons são ativados secundariamente, como é o caso de "preço de banana", "você é um banana" (ativação alta). Palavras como "amarelo" e "manga" são ativadas em menor grau (ativação média). Por fim, palavras como "banco", "céu" e "Netuno" permanecem inativadas (França, 2005). Isso nos faz lembrar das relações paradigmáticas de Saussure. Há outras relações entre língua e seu MA mental. Sabemos que o fasciculus arqueado (arcuate fasciculus) conecta reconhecimento fonológico a produção fonológica. Há até mesmo fatos gramaticais que são conhecidos como, por exemplo, a parte do cérebro que é ativada durante a produção e percepção de frases. O que se dá na interação social só tem continuidade e se torna parte da linguagem de um grupo se é armazenado nos cérebros dos membros de P. Só assim pode ser reutilizado e reciclado. Para Chomsky, por exemplo, o cérebro é o locus da linguagem, uma vez que ela é armazenada e processada em uma complexa rede de conexões neurais (sinapses).

Até onde sabemos, não há investigações deste ecossistema da perspectiva das relações entre língua e MA. No entanto, a psicolinguística, a neurolinguística e o 
conexionismo têm conseguido alguns resultados que podem ser aplicados na ecolinguística, como fora previsto por Haugen. Até mesmo a linguística neuro-cognitiva de Lamb (conhecida anteriormente como "gramática estratificacional") tem contribuído para o conhecimento do que se passa quando falamos ou ouvimos a fala de outrem. Para a discussão desse modelo, pode-se consultar Makkai (1993). Nós não temos muita informação sobre o que se passa com os conceitos espaciais no Ecossistema Mental da Língua, ou seja, o cérebro/mente. Porém, sabe-se que a aquisição das preposições pelas crianças em geral vai de "em" para "sobre e, em seguida, para "sob". Sabe-se, outrossim, que "próximo" precede "antes/depois". Às vezes, "entre" precede o último. Como se vê, a aquisição via de regra obedece a seguinte ordem: em/fora > sobre/sob $>$ antes/depois. Isso é uma evidência adicional para o que está dito sobre a ecologia das relações espaciais mais abaixo. Tem sido mostrado que itens lexicais como as preposições emergem quando a criança tem a experiência correspondente com o mundo. No entanto, há discordâncias sobre esse ponto.

\subsection{O Ecossistema Natural da Língua}

Entre os três ecossistemas que fazem parte do Ecossistema Fundamental da Língua, o Ecossistema Natural da Língua é o que tem sido mais relegado a segundo plano nos estudos linguísticos. No entanto, em outras áreas como a filologia pelo menos alguns de seus aspectos foram levados em conta. Como já vimos, os gregos já se preocupavam com as relações entre palavra e coisa. No entanto, as relações entre língua e MA natural não se restringem ao que se tem chamado de designação, denotação, referência etc. A relação entre língua e MA físico não se confina ao léxico. De acordo com Odgen \& Richards (1972, p. 52), para Heráclito "a estrutura da fala humana reflete a estrutura do universo".

Mais recentemente, John Haiman (1980) defendeu ideias semelhantes. Ele segue a asserção de Greenberg de que "a ordem dos elementos da língua está em paralelo com os da experiência física ou a ordem do conhecimento, como em veni, vidi, vici" (Haiman 1980, p.528). Ele conclui afirmando que "desde a revolução transformacional, tem se afirmado que a estrutura da língua reflete a estrutura do PENSAMENTO, e que o seu estudo [da língua] provê 'uma janela para a mente'. Ao argumentar, como temos feito, em prol da iconicidade da gramática em geral, nós defendemos a tese de que a estrutura do pensamento, por seu turno, reflete a estrutura da REALIDADE mais do que o modismo atual o admite. Por fim, acreditamos que sobre muitos (se não todos) os universais formais da sintaxe que atualmente atraem a atenção da maioria dos sintaticistas teóricos, descobrir-se-á que refletem propriedades do mundo, e não propriedades da mente em si. Descobrir-se-á que 'em parte mediante 
o estudo da sintaxe, poderemos chegar a um razoável conhecimento da estrutura do mundo"' [citando Bertrand Russel] (Haiman, 1980, p.537).

Há, pelo menos, duas maneiras de encarar as relações entre língua e MA Natural. A primeira recua até os gregos, como no Crátilo de Platão. Mais recentemente, ela está representada na tradição que vai de Hammann (1730-1788), passa por Herder (1744-1803) e Humboldt (1767-1788), chegando a Leo Weisgerber, para mencionar só quatro autores. De acordo com essa tradição, a língua se interpõe entre nós e o mundo, como se pode ver na Weltbild (visão de mundo) de Humboldt e na Zwischenwelt (entremundo) de Weisgerber. Nos Estados Unidos, essa tradição está representada por Boas (1858-1942), Sapir (1884-1939), e Whorf (1897-1941), culminando na conhecida Hipótese Sapir-Whorf. Algumas versões dessa linha de pensamento alegam que há uma simetria entre linguagem e mundo, como é o caso do primeiro Wittgenstein (1968) e, sobretudo, na representação gráfica de Helbig (1975, p. 124), reproduzida na figura 02.

Figura 02: Representação gráfica de Helbig (1975)

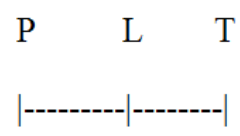

De acordo com esse ponto de vista, o mundo é construído pela linguagem, de modo que nós só temos acesso a ele através dela. Veríamos no mundo apenas o que nossa cultura e nossa linguagem nos mostram. No entanto, como Schaff (1974) demonstrou, trata-se de um ponto de vista idealista e místico, embora contenha alguma dose de verdade, ou seja, que cada língua categoriza o mundo de modo diferente. Como o filósofo norueguês Arne Naess (1997, p.2) disse, "nas experiências espontâneas nós temos acesso direto ao que é real". De acordo com ele, "nós não construímos coisas. Nós construímos conceitos de coisas" (ibid), ou seja, palavras, linguagem. Isso é um bom ponto de partida para a discussão da visão oposta à que está sendo discutida, no que concerne às relações entre língua e MA físico. Na verdade, é a população (P) que se interpõe entre língua e mundo. Tanto que Mufwene $(2001,2005)$ considera L como uma espécie parasita (ou viral) de $\mathrm{P}$, no sentido biológico. Essa idéia está representada na figura 03 .

Figura 03: Representação gráfica da população como interveniente entre língua e mundo

L $\quad \mathrm{P} \quad \mathrm{T}$

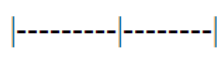


De acordo com essa segunda concepção das relações entre L e MA, aqui representado por T, nós temos acesso direto ao mundo. Entretanto, depois de formada, a língua adquire uma relativa autonomia vis-à-vis mundo. Assim, depois de ter os recursos para formar sentenças como "Fonemas oclusivos surdos e correm frequentemente", os falantes podem construir frases como "Ideias verdes incolores dormem furiosamente". Ambas são gramaticais. A gramática morfológica do português admite não somente "constituir, prostituir", por um lado, e "constituição, prostituição", por outro, mas também "constitucional, constitucionalidade, constitucionalismo" e "prostitucional, prostitucionalidade, prostitucionalismo". Essas formas são construídas pela reutilização e reciclagem de morfemas e regras morfológicas existentes, mesmo que algumas delas permaneçam inativadas. $\mathrm{Na}$ fonologia também há sílabas inativadas, como /fiès/. Ela é tão bem-formada quanto à contraparte com a vibrante / $/$, que ocorre em /fres/ (fres.ta). Tanto / flès/ é gramatical que se algum dia alguém inventar algum produto e lhe der o nome de "flesta" nenhum falante da língua acharia a forma estranha. Mas mesmo palavras monomorfêmicas podem ser recicladas (reativadas), contribuindo ainda mais para a relativa autonomia da linguagem frente ao mundo. Assim, "manga" pode indicar tanto uma parte do vestuário quanto uma fruta. Existem ainda as polissemias, as metonímias, as metáforas e assim por diante (Couto, 2007).

É essa autonomia relativa da linguagem em relação ao mundo que dá a impressão de que ela é independente dele (dada por Deus?) e maior do que ele, tendo o poder de criá-lo. Como L pode ser maior do que T, se está apoiada em $\mathrm{P}$, que vive em T? Como o parasita pode criar o organismo que o suporta? Enfim, desse modo, a linguagem poderia ser vista como uma imagem especular do mundo, como na tradição metafísica bem como em, por exemplo, o Tractatus logico-philosophicus (1968) de Wittgenstein.

A relação língua MA Natural pode ser examinada de outras perspectivas. Uma delas são as interações entre indivíduos pertencentes à mesma comunidade de fala. Essas interações se dão em um lugar específico. Assim, o simples fato de indivíduos se verem juntos em determinado espaço indu-los a interagir. A interação mais típica entre humanos é a linguística. A língua emerge dessas interações, fato que pode ser visto claramente no surgimento das línguas crioulas, em que há a convergência e interação íntima entre pessoas de diferentes origens culturais (linguísticas, de território etc.). Conceitos mentais existem devido à existência de estímulos físicos do mundo externo, no MA Natural da Língua, como se pode ver na Ecologia das Relações Espaciais vista mais abaixo. Nós não temos informação específica sobre o assunto, mas presumimos que em regiões montanhosas conceitos como "alto" e "baixo" seriam mais chamativos do que "sobre" e "sob". De 
fato, existe um caso paralelo mencionado por Sapir (1963), que, no seu famoso "Language and environment", menciona "o uso em kwakiutl e nutka, por exemplo, de sufixos locais indicando atividades que se dão na praia, nas pedras ou no mar". Entre os três ecossistemas do EFL, é o Ecossistema Natural da Língua que tem a ver diretamente com a Ecologia das Relações Espaciais e, consequentemente, com as preposições espaciais.

\subsection{Inter-relações entre os Ecossistemas Social, Mental e Natural da Língua}

A divisão dos ecossistemas da língua em três, apresentada na seção precedente, pode dar a impressão de que eles seriam independentes um do outro, que não haveria nenhuma relação entre eles. Nada disso. Uma vez que os conceitos e princípios que constituem as bases epistemológicas da ecolinguística são tirados da ecologia, a ideia de que tudo está relacionado a tudo fica sempre implícita. Como mencionamos na primeira parte desta seção, o conceito central da ecologia é o de ecossistema, que é definido como sendo as inter-relações que se dão entre organismos bem como entre eles e seu meio ambiente. Além disso, a vitalidade de um ecossistema depende de sua diversidade, especialmente a biodiversidade. Esses são os conceitos mais importantes da ecologia que têm sido usados nas ciências sociais, ou seja, a) ecossistema, b) inter-relações, c) diversidade. Inter-relações pressupõem movimento, dinamismo, com o que também o conceito de evolução deve ser incluído. Os ecossistemas da língua, e seus respectivos MA, são sistemas análogos. No interior do ecossistema geral, o Ecossistema Fundamental da Língua, há uma intenso inter-relacionamento entre os três sub-ecossistemas, ou partes deles.

Exemplifiquemos isso com as preposições guineenses apresentadas em (2), abaixo, tomadas de empréstimo ao português. A primeira vez que cada uma delas foi usada, foi proferida por um indivíduo e dirigida a outro no seio da comunidade (EIL) guineense. Isso foi um ato social, portanto, no contexto do Ecossistema Social da Língua. Mas, a informação para esse ato social teve início no cérebro do falante, onde foi associado ao respectivo significado. Do cérebro, ela foi transmitida aos órgãos da fala, de onde foram levadas ao ouvido do falante. Esse processo se dá no contexto do Ecossistema Mental da Língua. No entanto, o fato de ele ter se dado entre dois indivíduos, acaba envolvendo o Ecossistema Social da Língua. Por fim, toda a interação foi possível porque os dois interactantes estavam espacialmente próximos, no território da Guiné-Bissau, ou seja, no Ecossistema Natural da Língua guineense. Além do mais, o conceito só foi formado no cérebro dos falantes porque tiveram experiências com fatos do MA Natural. Enfim, quando falamos em um ou outro desses ecossistemas, estamos apenas focalizando a 
atenção em determinado ponto de uma imensa teia de inter-relações. Poderíamos mesmo dizer que é como um holograma, em que cada parte implica o todo e vice-versa (cf. Bohm, 2001).

$\mathrm{Na}$ verdade, tudo começa no Ecossistema Natural da Língua. É o encontro de dois membros da comunidade em um ponto específico de $\mathrm{T}$ que faculta a interação comunicativa. $\mathrm{O}$ que é mais, sempre que duas pessoas se veem juntas espácio-temporalmente elas interagem. A interação começa como um processo psíquico e se torna social. Enfim, tudo começa no Ecossistema Natural, passa pelo Ecossistema Mental e é sancionado pelo Ecossistema Social da Língua. As inovações sempre emergem no Ecossistema Mental, onde podem ficar armazenadas. Elas só têm continuidade se foram compartilhadas por outros membros da comunidade, Ecossistema Mental. Por fim, sem o Ecossistema Natural, nada disso seria possível. O fato é que há um constante inter-relacionamento entre os diversos ecossistemas da língua, de modo que às vezes é difícil dizer onde começa um processo e onde termina outro. O começo é o fim, e vice-versa. Frequentemente, tudo se dá simultaneamente, quando não em ciclos.

\section{Ecologia das Relações Espaciais}

Os estudos das relações entre a língua e mundo têm se restringido ao léxico, como se pode ver na tradição filosófica (relação palavra-coisa) mencionada acima, como em Sapir ([1963] 2001, p. 90). De acordo com esse autor, "é o vocabulário da língua que mais claramente reflete o meio ambiente físico e social de seus falantes". No entanto, há algumas exceções à ideia de que só léxico se relaciona com o MA, como pode ser visto em Heráclito e nas ideias de John Haiman (1980), lembrados acima. Mas, mesmo no léxico, os estudos têm se restringido às palavras referenciais, isto é, que designam algo fora da língua. O que nós pretendemos fazer aqui é investigar as relações que se dão entre língua e um tipo de palavras tidas como não referenciais, ou seja, as preposições, consideradas palavras gramaticais, categorias funcionais.

A fim de preparar o terreno, é importante apresentarmos a Ecologia das Relações Espaciais em geral. A ideia em si recua a, pelo menos, 1668, ano em que John Wilkins representou essas relações em um modelo bidimensional. Ele pôs um observador em frente a um ponto de referência que consistia de dois círculos concêntricos. Primeiro, ele apresenta uma seta "para baixo", cujo resultado é "abaixo", bem como outra "para cima", que resulta na relação "acima". Em seguida, temos as seguintes relações: a) "dentro" versus "fora", b) "para dentro" versus "para fora", c) "sobre" versus "sob", d) "aquém" versus "além", e) "a/para" versus "de/desde". As seguintes relações não são dicotômicas em seu modelo: f) "sobre" (about), g) 
“acima” (over). Algumas posições em seu esquema não estão muito claras para nós. Por exemplo, h) "embaixo” (below) está entre o observador e o círculo, mas um pouco abaixo do diâmetro dele, não abaixo dele. Além do círculo central, de novo da perspectiva do observador, Wilkins inclui: i) "através de" e k) "além de". Fora do círculo maior, temos 1) "a/para" (to) versus "de" (off). Finalmente, veem-se m) "após" (to the back of the observer, sic!) versus "antes" (in front of him, i.e., between him and the point of reference).

Como se pode ver facilmente, há diversas inconsistências na representação de Wilkins (1668). A mais flagrante delas é o posicionamento de "after". Essa palavra deveria ter sido colocada no lado oposto do círculo em relação ao observador, não antes dele. Além disso, "against", "through", "besides"e "without" estão colocados depois do ponto de referência. Só a última pertence a essa posição. Finalmente, a posição indicada pela preposição por excelência, ou seja, "em” (in), e sua contraparte "fora" (out) estão ausentes de seu esquema. Talvez isso se deva ao fato de Wilkins tratar apenas de preposições de movimento, como Eco (2002, p. 319) notou. De qualquer forma, não devemos ser excessivamente rigorosos com ele. O seu estudo é provavelmente a primeira tentativa na história dos estudos linguísticos de representar a Ecologia das Relações Espaciais. Bernard Pottier $(1962,1969)$ também estudou as preposições a partir do conceito de espacialidade, embora suas representações sejam unidimensionais apenas. Baseando-se em Gustave Guillaume, ele sugere o que está representado na figura 04, em que tudo está antes ou depois do ponto de referência. Pottier inclui outras categorias de palavras espaciais, não apenas preposições (Pottier, 1962; 1969).

Figura 04: Representações de palavras espaciais segundo Pottier

\begin{tabular}{|c|c|}
\hline $\mathrm{a}$ & de \\
\hline até & desde \\
\hline antes & depois \\
\hline sob & sobre \\
\hline ....... & $\mathrm{e}$ \\
\hline ........ & mais \\
\hline
\end{tabular}

Eu havia proposto em minha dissertação de mestrado um modelo tridimensional para a Ecologia das Relações Espaciais, sem saber da sugestão Wilkins (Couto, 1973, p. 45). Nos anos noventa, eu retornei ao assunto, em um livro dedicado a uma visão geral do crioulo guineense (Couto, 1994, p.122). Essa segunda versão da proposta está reproduzida na figura 05 . 
Figura 05: Modelo tridimensional
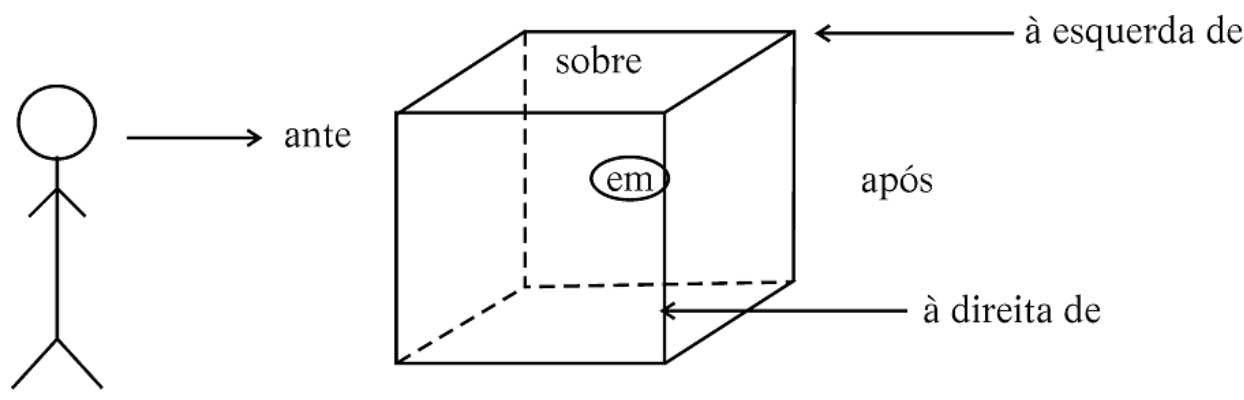

O ponto central dessa ecologia é a interioridade. Isso se deve ao fato de ela não exigir um observador. Assim, o caroço no interior de uma fruta está objetivamente lá, independentemente de haver alguém para observá-lo ou não. Por isso, ela é considerada a relação espacial não-marcada, ao lado de seu oposto, a exterioridade. Não é de admirar que a preposição que a codifica (em) seja a preposição espacial não-marcada, inclusive a que codifica a relação oposta (fora de). A relação de interioridade versus exterioridade, independe da horizontalidade e da verticalidade, que são importantes para a relação de superioridade/inferioridade, representadas por "sobre" e sob". No entanto, se traçarmos uma linha vertical partindo de "sobre" até "sob", ela passará por "em", ponto pelo qual passaria a linha horizontal. A relação indicada por "em” está no cruzamento das duas. Tanto que Lyons (1977, p.699) afirma que "a noção de continência, ou interioridade, é claramente uma noção básica", de modo que "parece haver fundamentos para introduzi-la na análise do significado de preposições como 'acima', 'abaixo' etc”. Vandeloise (1991, p. 34) acrescenta que "a relação extralinguística de continente/ conteúdo [é] praticada pela criança bem antes de a língua ser plenamente adquirida".

Voltemos à relação de superioridade/inferioridade. Também elas são independentes de um observador. Por exemplo, uma pedra pequena em cima de uma maior está lá objetivamente, quer haja um observador, quer não. Por esse motivo, ela vem logo depois de "dentro/fora" na escala de marca. Melhor dito, ela é a segunda não-marcada. Se a relação "sobre-[em]-sob" se localiza ao longo do eixo vertical, "antes-[em]-depois" alinham-se ao longo do eixo horizontal. No entanto, diferentemente das relações anteriores, a anterioridade e a posterioridade dependem do observador. Um objeto só pode estar "antes de" ou "depois de" outro relativamente a alguém que o olha, como se pode ver na figura 05 . Por isso, essas duas relações são bem mais marcadas do que as anteriores, e adquiridas bem mais tarde pela criança. Ainda no eixo da horizontalidade, temos as relações de 
dexteridade (à direita de) e sinistridade (à esquerda de). Na maioria das línguas europeias, elas são expressas por locuções, não por preposições simples. Elas são as mais marcadas de todas as que compõem a Ecologia das Relações Espaciais.

As relações vistas na figura 05 são relações espaciais prototípicas, no sentido da teoria dos protótipos (Rosch, 1975; Colemen \& Kay 1981; Bärenfänger, 2005). As demais relações espaciais podem ser derivadas delas de um modo ou de outro. É o caso das preposições de movimento, como as representadas no esquema de Wilkins. O que é mais, mesmo as demais relações, ou seja, inclusive as "não espaciais" seriam derivadas delas. Nós gostaríamos de observar que as relações representadas na figura 05 não exaurem todas as relações espaciais possíveis, apenas as que podem ser codificadas por preposições ou locuções prepositivas. Por exemplo, ao longo da dimensão vertical, há posições como "alto" versus "baixo". Ao longo da dimensão horizontal temos relações dêiticas como "próximo" versus "longe", entre outras. Entre as outras, teríamos "largo" versus "estreito", "longo" versus "curto" e assim por diante (cf. Greimas, 1966, p. 33).

\section{As preposições crioulas: um apanhado geral}

De acordo com Kihm (1994, p. 67), o guineense tem preposições simples, como em (1a), e preposições complexas, como em (1b).

(1) (a) a 'a', entremetadi 'entre', kontra 'contra', ku 'com', na 'em', pa 'a, para', sin 'sem', suma 'como', te 'até'

(b) antis di 'antes de', (na) banda di 'próximo a', bas di 'sob', dentru di 'em, dentro de', dianti di 'antes de', dipus di 'após', disna di 'desde', filadu di 'defronte a', fora di 'fora de', juntu di 'perto de', lungu di 'ao longo de', lunju di 'longe de', na metadi di 'entre', na roda di 'próximo, por', pa bia di 'por causa de', riba di 'sobre', pertu di 'perto de', te 'até', tras di 'atrás de'.

Além das incluídas nessa lista, há preposições que são claramente empréstimos recentes ao português. Algumas delas estão reproduzidas em (2).

(2) entri 'entre', anti 'antes de', sugundu 'segundo', cunformu 'de acordo com'

Há até mesmo algumas construções que, a despeito de não serem claramente prepositivas, são equivalentes a locuções prepositivas, uma vez que se referem a relações espaciais. Vejamos alguns exemplos em (3).

(3) (a) Maria bai na si tras 'Maria foi no seu traseiro = Maria foi atrás dele'

(b) Jon sta na si dianti 'João estão no seu dianteiro = João está na frente dele'

(c) Jugude bua na si ladu 'o abutre voou no seu flanco $=\mathrm{o}$ abutre voou ao seu lado'

Alain Kihm (1994) aceita a ideia de que a preposição por excelência no crioulo guineense é a que codifica os significados de "estar-no-interior", "estar-na- 
-superfície-de", "estar-em-uma-localização". Trata-se, como se vê, da preposição que codifica interioridade, $n a$ 'em, dentro de'. Os exemplos do autor estão reproduzidos em (4).

(4) (a) i sta na kuartu 'ele/a está no quarto'

(b) i sta na mesa 'ele está na mesa'

(c) i sta na fera 'ele/a está no mercado'

Examinemos a frequência das preposições guineenses com o fito de aquilatar sua vitalidade na língua. Nós contamos preposições simples e preposições complexas em nove fábulas e em uma longa fala de um político. O primeiro texto é basiletal; o segundo, acroletal. Os resultados estão expostos na tabela 01 .

Tabela 01: Preposições

\begin{tabular}{|c|c|c|c|}
\hline \multicolumn{5}{|c|}{ PREPOSIÇÕES } \\
\hline SIMPLES & OCORRÊNCIAS & COMPLEXAS & OCORRÊNCIAS \\
\hline $\mathrm{Di}$ & 216 & dentru di & 10 \\
\hline $\mathrm{na}$ & 114 & riba di & 7 \\
\hline $\mathrm{ku}$ & 58 & pertu di & 5 \\
\hline $\mathrm{pa}$ & 34 & antis di & 3 \\
\hline suma & 11 & na metadi di & 2 \\
\hline kontra & 6 & dipus di & 2 \\
\hline Te & 6 & pabia di & 2 \\
\hline kuma & 4 & bas di & 1 \\
\hline sim & 2 & trás di & 1 \\
\hline desdi/dedi & 1 & na roda di & 0 \\
\hline disna & 0 & pa ladu di & 34 \\
\hline Total & 452 & Total & 1 \\
\hline
\end{tabular}

Como se vê, a preposição mais frequente é $d i$, não $n a$, como seria de se esperar. No entanto, isso certamente se deve ao fato de ela ocorrer em muitas locuções, prepositivas ou não, como em manga di 'uma grande quantidade de', gosta $d i$ 'gostar de', dibi di 'dever, poder', di maña/tardi/noti 'de manhã/tarde/noite'. Assim sendo, é provável que a preposição mais frequente em posição claramente prepositiva seja $n a$. Com efeito, ela aparece 47 vezes combinada com outros morfemas, como nel 'nele', nunde/nde 'onde', embora di também possa ocorrer nesse tipo de combinação: del/delis 'dele/deles', mas apenas nove vezes. Se contarmos a partícula verbal $n a$, que indica aspecto não-pontual na terminologia de Bickerton (1981) como em Jon i na fuma 'João está fumando', na será certamente mais frequente do que di. Em 1.176 ocorrências, na é partícula verbal 690 vezes $(58,67 \%)$, e preposição 486 vezes $(41,32 \%)$. Como Claire Lefebvre (1998) 
sugeriu, com razão, sobre morfemas similares do haitiano, na é uma partícula multifuncional. As duas vêm da combinação da preposição portuguesa "em" mais o artigo feminino "a". Assim, uma seria preposição com nomes, a outra "preposição" com verbos. Tanto que preposição é neutra em relação aos traços nome $(\mathrm{N})$ e verbo $(\mathrm{V})$, ou seja, $-\mathrm{N},-\mathrm{V}$.

A terceira e a quarta preposições mais frequentes no guineense são $k u$ e $p a$. Também elas podem combinar-se com outros morfemas, mas em menor grau. Em nossas estatísticas, $k u$ aparece 6 vezes em combinações como kel 'com ele' e uma vez em kelis 'com eles'. $P a$ aparece em par maña 'de manhã' (uma vez) e em par'el 'por ele' (duas vezes). As preposições guineenses apresentam outras peculiaridades que merecem ser mencionadas. Uma delas é o fato de riba di (sobre) poder aparecer sob a forma de na riba di. Outra é o alto número de preposições complexas tomadas de empréstimo ao português, sobretudo em registros acroletais. No discurso mencionado acima, nós encontramos ao lado d'el 'ao seu lado' e pa/por exemplo 'por exemplo'. Por sinal, esses exemplos acrescentam outras cinco ocorrências de $p a$. Finalmente, o texto acroletal contém também uma ocorrência de na frenti (na frente). Deve ser ressaltado que as preposições $k u$ e $p a$ funcionam também como complementizadores. A primeira aparece em construções como rapas ku ka misti tarbaja (o rapaz que não queria trabalhar). A segunda pode ser vista em sentenças como $N$ mist pa bu bai (eu quero que você vá).

\section{A Ecologia das Relações Espaciais nas preposições crioulo-guineenses}

Nesta seção, nós examinamos as preposições crioulas à luz da Ecologia das Relações Espaciais representadas pela figura 05. Voltando à lista de preposições de (1a) acima, vemos que o único equivalente de preposição simples portuguesa é $n a$. A fim de preencher as demais funções, temos que lançar mão de preposições complexas, como se vê em (5)

(5) em $=$ na, dentru di $\quad$ sobre $=$ riba di $\quad$ antes de $=$ antis di

$$
\text { após }=\text { dipus di } \quad \text { sob }=\text { bas di }
$$

Já vimos que em inglês as crianças aprendem "em" primeiro. Em seguida, vêm "em cima de", "embaixo de" e "próximo a", nessa ordem. Em geral, as preposições a serem adquiridas em seguida são "atrás de" e "na frente de". Se compararmos esses achados com as estatísticas de ocorrência das preposições guineenses do quadro 1, veremos que elas coincidem em parte. As duas preposições mais frequentes são $n a(\mathrm{em})$ e riba di (em cima de), nessa ordem. No entanto, há uma discrepância, uma vez que bas di (embaixo de) é a menos frequente, o que pode dever-se à paucidade de dados que compulsamos. No entanto, o número de ocorrências das outras duas confirma a ordem de aquisição, ou seja, após na e 
riba di emerge dipus di. Como já foi notado por investigadores, entre os nomes crioulos para as relações em questão, $n a$ não é apenas um lexema monomorfêmico, mas também um monossílabo. Todas as demais são preposições complexas. Todas consistem de um advérbio ou de um nome seguido pela preposição $d i$. Isso é um argumento adicional a favor da asserção de que na é a preposição por excelência. Ela existe em praticamente todos os crioulos de base lexical portuguesa e espanhola, bem como em variedades não crioulas dessas línguas, tais como o espanhol portorriquenho e o cubano.

Ela foi constatada até mesmo em crioulos de outras bases lexicais, como o sranan, o st. lucian, o trinidadiano e, talvez, no crioulo holandês das Ilhas Virgens, no jamaicano e no krio (Thompson, 1961, p. 112). Em algumas variedades populares, coloquiais e/ou dialetais do português brasileiro, a forma ni pode ocorrer no lugar de em. Parece haver uma relação entre ni e na. Poderíamos apresentar mais um argumento em prol da tese de que na é a preposição por excelência. Trata-se do fato nada trivial de que ela pode preencher praticamente todas as posições da figura 05 , como se pode ver nos exemplos abaixo (6). Mas o argumento mais forte é o de que ela codifica a posição nuclear da Ecologia das Relações Espaciais, ou seja, a de interioridade.

(6) (a) lebri sta na si koba 'o coelho está em (dentro de) seu buraco'

(b) lebri sai na si koba 'o coelho saiu de seu buraco'

(c) libru sta na mesa 'o livro está na (em cima de) mesa'

(d) Jon sta na bu tras 'João está atrás de (depois de) você'

(e) mininu na kuri na bu dianti 'o menino corre na sua (de você) frente'

(f) Jon bai na bu kasa 'João foi a sua casa'

Com respeito às posições "à direita/esquerda de", o equivalente mais próximo que consegui encontrar é na ladu di (ao lado de), exemplificado em (3c). Essa expressão indica lateralidade em geral, como outras expressões de (3) mostram. Vimos que a dimensão antis di - na - dipus di normalmente se alinha ao longo do eixo horizontal. No entanto, dependendo da posição do observador e do objeto observado essas expressões podem indicar outras orientações, como horizontalidade, obliquidade etc. Por exemplo, na direção para cima, poderíamos dizer que um mico está "antes" de um pássaro nos galhos de uma árvore, se olharmos a partir do solo. Se estivermos olhando de um helicóptero, por outro lado, o mico estaria depois do pássaro. A relação das posições em questão com o MA Social da Língua é apenas indireta. É o caso de alguns usos sociais de certas posições espaciais. No português brasileiro, "estar por dentro" significa conhecer, e "estar por fora", desconhecer. Em inglês, algo "in" é desejável, ao passo que "out" não o é. Na tradição cristã, o céu está acima de nós, enquanto que o inferno está abaixo de 
nós (aliás, infernus pertence à mesma família etimológica que "inferior"). Como se vê, "sobre/acima/por cima" é bom; "sob/abaixo/de baixo/embaixo", não.

Ainda no Brasil, estar "por cima" de algo significa dominá-lo, em todos os sentidos da expressão; estar "por baixo" indica o contrário. Aparentemente, essa oposição tem a mesma conotação no crioulo. Há uma fábula intitulada "Gera di gintis di riba ku gintis di bas", isto é, "Guerra das pessoas de cima (aves) com as de baixo (outros animais)". É o primeiro grupo que vence a guerra. Nas sociedades ocidentais, estar "na frente de" ou "à frente de" é considerado como estar em melhor situação, e estar "atrás de" significa estar em situação pior. A palavra portuguesa para o oposto do conceito de "estar à frente de" é "ser atrasado", derivado de "atrás". O bom é estar "avançado" (de avante < latim abante, que contém "ante"), na "vanguarda" (do francês avant-garde, também do latim abante). A distinção "à esquerda/direita de" também tem conotações sociais, políticas. Um "esquerdista" se considera mais consciente, democrático e liberal do que um "direitista". Esse conceito se originou na Revolução Francesa. Nas reuniões da Assembleia Legislativa (1791-1792), a aristocracia, os jacobinos, sentavam-se à direita, enquanto que os democratas, os girondinos, se postavam à esquerda.

\section{Outras preposições espaciais crioulo-guineenses}

Como se pode ver na Tabela 1, existem outras preposições no crioulo que indicam relações espaciais, além das que foram elencadas em (5). Entre elas, temos entremetadi (entre), na metadi di (entre), na roda di (ao longo de), (na) banda di (próximo, em volta de), filadu di (defronte a), fora di (fora de), juntu di (perto de), lungu di (ao longo de), lunju di (distante de) e pertu di (perto de). Todas elas indicam relações estáticas, como as de (5). Além disso, há as preposições da figura 06.

Figura 06: Preposições do crioulo-guineense

\begin{tabular}{l|l} 
pa & di \\
te & de(s)di, disna (di) \\
antis di & dipus di \\
bas di & riba di \\
fora di & na, dentru di
\end{tabular}

As duas primeiras preposições da figura 06 são usadas tipicamente com verbos de movimento, como indicado pelas setas. São as formas que entram no esquema de Bernard Pottier (1962). No entanto, é importante lembrar que o que indica direcionalidade não são as preposições em si mesmas, mas os verbos que 
coocorrem com elas. O máximo que podemos dizer é que elas são compatíveis com esse tipo de verbo. De qualquer forma, continuaremos a usar a expressão "preposições de movimento". Aqui se incluem subespecificações do movimento, tais como direcionalidade, origem, percurso e destino (Bennett, 1975). As preposições de movimento crioulas são precisamente $p a$ (a, para) e dedi (desde, de). Mas, te (até) e di também entram nessa categoria. De acordo com o modelo de Pottier (1962), todas as preposições, bem como alguns advérbios e até outras categorias de palavras, entram de um lado ou outro da linha vertical da figura 06. Como se pode ver mais detalhadamente na figura 06, além das preposições prototipicamente direcionais, as formas bas di/riba di, fora di/dentru di não são obviamente direcionais.

Pottier (1962) afirma que o lado esquerdo da linha vertical indica aferência, ao passo que o lado direito indica deferência. Ele acrescenta que o primeiro "propõe", indica aproximação; o segundo "dispõe", indica distanciamento. Com essa informação adicional, fica mais fácil aceitar bas di e fora di no lado esquerdo e riba di e dentru di no lado direito. Quanto a na, não fica muito claro, à primeira vista, porque ela entra no lado direito, sobretudo se considerarmos construções como as de (18), que indicam alvo. Aparentemente, ela deveria ser colocada em cima da própria linha vertical, uma vez que pode substituir qualquer posição no espaço, como já vimos.

\section{Preposições aparentemente não-espaciais no guineense}

Algumas preposições parecem não ser espaciais, pelo menos à primeira vista. Entre elas poderíamos mencionar $k u$ (com), sin (sem), suma/sima (como), kontra (contra) e pa bia di (por causa de). No entanto, segundo Pottier todas devem entrar em um lado ou outro da linha vertical. Com respeito a $k u$, Pottier (1962, p. 279) sugere que seu equivalente latino é uma variante de $a d$ (a, para, em direção a), uma típica preposição espacial, direcional. Sobre seu equivalente inglês, John Lyons disse que "o que John is with Peter significa é John está onde Peter está" (Lyons, 1975, p. 693). De um ponto de vista puramente lógico, ku indica a relação de conjunção, isto é, simultaneidade de duas coisas no espaço. Outro argumento a favor dessa interpretação é o fato de que $k u$ tem a função do "e" português. Muitas fábulas crioulas (e africanas) têm por título storia di ubu $\underline{k u}$ lebri (estória da hiena e do coelho). Quanto a $\sin$ (sem), é o oposto diametral de $k u$, portanto, se articula ao longo do mesmo eixo. Se Pottier estiver certo ao alinhar todas as preposições com para/até ou com de/desde, respectivamente, em seu modelo, então todas as preposições espaciais têm essa conotação. Vejamos o caso de suma e sima, como exemplificados em (7). 
(7) (a) bu firma suma po 'você está de pé como uma árvore'

(b) sima fonti na kamiñu 'como uma fonte ao longo do caminho'

Para começo de conversa, suma e sima parecem ser simples variantes fonológicas de uma mesma preposição. Há diversas outras alternâncias $i / u$ na língua. As conjunções $s i$ (se) e $k i$ (que), por exemplo, têm as variantes $s u$ e $k u$, respectivamente. Além disso, sima é muito raro, não tendo ocorrido em nosso corpus. O que é mais, em todos os demais textos que já vimos, ela ocorreu apenas duas ou três vezes. Alguns autores consideram kontra uma preposição. Entretanto, em nosso corpus essa forma ocorreu como verbo (8a), advérbio (8b) e como conjunção (8c) precedida de si (se), mas não como preposição. Esses autores devem tê-la visto em uma variedade descrioulizada do guineense. Nesse caso, tratar-se-ia de uma interferência do português "contra".

(8) (a) bu ba kontra gora ku un algin 'você vai se encontrar com alguém agora'

(b) kontra kau firia omi bin sai di si kasa 'quando o local ficou frio, o homem saiu de sua casa'

(c) si kontra bu papia son, ami $\mathrm{N}$ fugial 'se você ficar falando, eu atiro em você'

Parece que todas as preposições podem indicar também noção, no sentido de Pottier (1962). Algumas delas serão discutidas na seção seguinte. Para iniciar a discussão sobre pa bia di, partamos do equivalente português "por causa de". Como se vê, ela contém a forma "causa", que é algo que precede algum efeito. Por isso, conteria temporalidade e, consequentemente, espacialidade, por motivos que serão discutidos mais abaixo. Originariamente, todas essas preposições podem ter sido claramente espaciais, como sugerido por Pottier. Não apenas relações temporais, mas também as relações "puras" (lógicas). Em suma, é altamente provável que geneticamente a maioria das preposições tenham emergido para indicar relações espaciais. Subsequentemente, elas podem ter sido usadas com conotações temporais. Só em uma terceira fase, elas devem ter sido usadas para indicar apenas noção, ou seja, conceitos abstratos. A ordem genética seria, então: relações espaciais > relações temporais > relações (Pottier, 1962). Voltaremos a isso na seção 12.

\section{As preposições temporais crioulas}

A dimensão horizontal "antes-em-após" da figura 05 podem ser vistas como um subconjunto da parte da Ecologia das Relações Espaciais que indica relações lineares. Pois bem, uma vez que a tradição cristã ocidental vê o tempo como uma linha, as preposições que aí entram para indicar relações espaciais poderiam 
indicar também relações temporais. É o que de fato ocorre, como se pode ver na figura 07 e nos enunciados em (9):

Figura 07: Preposições indicativas de relações espaciais e temporais

na

antis di|dipus di

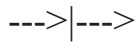

(9) (a) i kume antis di si dunu 'ele comeu antes de seu dono'

(b) ña pape ku bu pape na si tempu ba 'meu pai e seu pai no tempo deles'

(c) N bai dipus di Bisenti 'eu vou depois de Vicente'

No que tange a $n a$, deve ser ressaltado, no entanto, que em nossos dados ela ocorreu em construções temporais somente junto a palavras temporais tais como tenpu (tempo), dia (dia), апи (ano) e mis (mês), como nos exemplos mencionados no final da seção 12. Inclusive as outras duas expressões (9a, c) ocorreram em muito poucas frases. Há preposições espaciais usadas também em funções temporais. No entanto, no crioulo existe pelo menos uma preposição que só é usada em função temporal, no caso, disna (di), como exemplificado em (10):

(10) (a) N sta li disna k'u bai 'eu estou aqui desde que você se foi'

(b) N ka kume nada disna de parmaña 'eu não comi nada desde a manhã'

Embora dedi/desdi possa ocorrer com nesse também, disna só é usado para ele. Por outras palavras, disna é usado só temporalmente (11a), ao passo que dedi pode sê-lo espacial (11b) e temporalmente (11c), embora nós não tenhamos conseguido muitos exemplos:

(11) (a) N ka kume nada dedi aonti 'eu não comi nada desde ontem'

(b) bu ta kumsa cora desde kanpada di kasa 'você começou a chorar desde o campo de colmos'

Em alguns dialetos do português brasileiro, encontramos a forma desna que tem um significado parecido ao de disna. Aparentemente, teriam a mesma origem, ou seja, a forma desde $+n a$. Infelizmente, não temos maiores informações sobre essa etimologia. O único uso temporal de di que encontramos se deu em expressões fixas como di dia (de dia), di noti (de noite) e di menoti (à meia noite).

Com relação a te, ela indica relação temporal, como em (12):

(12) Jugude ka ojal mas te aos 'o abutre não encontrou-o até hoje'

Bennett (1975) reconhece um significado subjacente único para cada preposição. Esse significado subjacente pode ser realizado espacial e temporalmente. $\mathrm{Na}$ seção seguinte, veremos que há o uso nocional também, não levado em conta por Bennett. Em suma, há uma preposição usada apenas para relações espaciais. No 
entanto, é bem provável que na origem ela tenha sido espacial, como fica sugerido em sua provável etimologia.

\section{Preposições nocionais}

Segundo alguns investigadores, especialmente gerativistas, existem relações abstratas, puras. Essas relações não teriam nada a ver nem com espaço nem com tempo. Entre as que entrariam nessa categoria estão as que estão exemplificadas em (13):

(13) (a) storia di kasamenti di fiju di reglu 'história do casamento do filho do régulo'

(b) e dibi di ciga 'eles devem chegar'

(c) N misti papia ku bo 'eu quero falar com você'

As duas primeiras ocorrências de $d i$ em (13a) são nocionais, ou seja, inespaciais e intemporais. A terceira é genitiva. No entanto, se examinarmos o significado subjacente delas, verificaremos que a "história" gira em torno (conceito espacial) do "casamento", enquanto que o "casamento" pertence à filha do rei. O genitivo indica que, de alguma maneira, a filha provém do rei. A origem dela está, materialmente, nele. Em geral, ' $X$ tem p' pode ser analisado como 'p está em X' (Lyons, 1977, p. 722-724). O mesmo pode ser dito de 'p é de X'. Quase idêntico ao caso de ku, como já vimos. Pottier afirma que, em princípio, todas as preposições podem ser usadas no que chama de domínios espaço, tempo e noção. $\mathrm{O}$ último equivale ao das preposições "puras". De acordo com ele, noção é redutível a tempo, que é redutível a espaço. Vejamos o exemplo (14):

(14) kila ka sta na si plano 'aquilo não está em seus planos'

Nesse caso, $n a$ está sendo usada nocionalmente, em um sentido abstrato. Não haveria temporalidade nem espacialidade nela. No entanto, deve ser notado que a interpretação é de que "algo está localizado em seu plano". Em (15), temos $d i$ e $k u$ na mesma sentença:

(15) Sara papia di Jon ku Maria 'Sara falou de João com Maria'

Aparentemente, as duas são apenas nocionais. No entanto, "falar de" é o mesmo que "falar sobre" e, como sabemos, o sentido básico de "sobre" é espacial. Além disso, já vimos que "falar a alguém" ou "com alguém" é o mesmo que falar e estar no mesmo lugar em que alguém se encontra, como já vimos com Lyons. A construção com verbo serial de (20) vai no mesmo sentido. Todas as relações são redutíveis à espacialidade, e não apenas a temporalidade, mas também as relações "lógicas", "puras", nocionais. Quando examinamos a etimologia delas, notamos que praticamente todas têm origem espacial. Inclusive sincronicamente, algumas preposições da Ecologia das Relações Espaciais, da figura 05, podem ter 
um uso secundário, temporal e/ou nocional, como "sobre" do português e about do inglês.

\section{Alguns usos aparentemente estranhos de preposições espaciais crioulas}

Existem alguns usos de preposições espaciais crioulas que parecem estranhos a falantes de línguas de origem europeias. No entanto, quando analisamos esses usos a fundo à luz da Ecologia das Relações Espaciais, e cientes de que natura non facit saltus, constatamos que não há nada de estranho nesses usos. Vejamos os exemplos de (16):

(16) (a) i sai na si koba 'ele saiu em sua toca, i.e., de sua toca'

(b) bajuda sai na kunbu di po 'a moça saiu no buraco da árvore, i.e., do buraco'

(c) i tira fijo na dentru di galiña 'ele tirou seu filho na galinha, i.e., da galinha'

(d) bo sai na matu 'você saiu no mato, i.e., do mato'

(e) iagu ta sai na uju 'água está saindo em seu olho, i.e., de seus olhos'

Nesses exemplos, $n a$ está sendo usada no sentido de "de" ("out of", em inglês). Na verdade, na é estático, indica a locação e, quando muito, objetivo ("vou em São Paulo"), não origem. Como explicar seu uso mostrado em (16)? Vejamos o que Bickerton (1981) diz sobre deslocamento de outro tipo de significação, que tem algo a ver com "em". Baseando-se na aquisicionista Eve Clark, ele apresenta as quatro relações mostradas na figura 08 :

Figura 08: Quatro relações

\begin{tabular}{|c|c|}
\hline Proriedade & localização \\
\hline Posse & Existência \\
\hline
\end{tabular}

Bickerton (1981) afirma que Eve Clark "examinou os modos pelos quais essas relações são apresentadas numa amostra de cerca de 50 línguas". Ele aplicou o mesmo princípio à análise dos artigos crioulos. Aplicando sua argumentação ao guineense, podemos dizer que o morfema que indica posse indica também existência, como mostrado em (17). A tradução mostra que em português acontece a mesma coisa.

(17) (a) Jon tene libru 'João tem um livro'

(b) I ka tene libru li 'não há livru aqui', i.e., 'não há livro aqui'

Bickerton conclui que "nenhuma língua pode usar o mesmo morfema para expressar relações não-contíguas (i.e., localização e posse, ou existência e propriedade) a não ser que o mesmo morfema seja usado também para indicar a relação interveniente" (Bickerton, 1981, p. 244-245). No crioulo, a preposição que codifica a posição de interioridade codifica também a ideia de ponto em uma 
linha. Uma vez que na Ecologia das Relações Espaciais ela está adjacente tanto a "antes de" quanto a "depois de", ela poderia, em princípio, substituir ambas as relações, bem como qualquer uma das demais posições da figura 05. Assim sendo, não deveria ser considerada estranha a existência de construções como as de (16). No latim (18a) e no português brasileiro (18b), o equivalente de $n a$ (em) pode indicar "em direção a".

(18) (a) Eo in Romam 'vou a Roma'

(b) Eu vou lá em Roma

Até mesmo a expressão complexa para indicar "no interior de", ou seja, dentro $d i$, pode ser usada na função de (16), como mostrado em (19).

(19) no tira tuga na dentru de no tera 'nós tiramos os portugueses de nossa terra'

$\mathrm{O}$ uso de dentru di substituindo na já é estranho a nossos olhos. No entanto, (19) mostra que a noção de interioridade da figura 05 realmente pode deslizar para as noções vizinhas. Davida Bennett afirma que to the church seria mais claramente indicado por *to at the church (Bennett 1975: 18). O uso de na em (16) seria mais inteligível para nós se a expressão fosse * di na koba. No entanto, deve ser lembrado que $n a$ é a preposição por excelência no crioulo, fato que, por si, já tem a ver com a interioridade. Assim, de acordo com a fig. 05 , ela poderia substituir todas as formas adjacentes. O terceiro tipo de construções semelhantes a preposições que nós gostaríamos de discutir brevemente é o que se vê ilustrado em (3) acima. Embora Kihm (1994, p. 68) afirme que essas construções "são frases fixas, o que implica que devem ser mencionadas especificamente na entrada lexical para diyanti (sic) e tras", nós achamos que o fato de termos um uso adicional da preposição por excelência na é mais importante.

Por outras palavras, si tras (seu traseiro) e si dianti (sua parte dianteira) são sintagmas nominais que adquiriram valor preposicional pela simples adição de $n a$. $\mathrm{Na}$ verdade, esse procedimento pode ter sido a origem de muitas preposições espaciais, como foi sugerido alhures neste artigo, ou seja, tomar como ponto de partida um nome que indica uma parte do espaço, ou uma parte do corpo do observador. Alguns objetos se posicionam "antes de" (no lado da bunda), "em frente de" (no lado da cara), "dentro de" (no interior do estômago, da boca, p. ex.), "no lado do braço esquerdo" (à esquerda de) ou "no lado do braço direito" (à direita de).

\section{As "locuções complexas" são efetivamente preposições complexas ou constam de preposições simples e algo mais?}

Alain Kihm (1993) divide as preposições crioulas em simples e complexas. No entanto, isso é uma categorização prática, longe de ser unânime. Como o 
próprio Kihm notou, "todas as preposições complexas são compostas de di precedido de um elemento que pode ser um adjetivo (lunju 'longe', juntu, um advérbio (bas como em $i$ sta la bas 'ele/a está lá embaixo', dentru, disna 'desde', filadu 'em frente', fora, lungu 'ao longo', riba 'em cima'), ou um nome (banda 'lado', diyanti, tras) (Kihm, 1993, p. 67-68). Se levarmos em conta que lungu e juntu não são adjetivos prototípicos, mas advérbios, podemos analisar as chamadas "preposições complexas" como uma construção que contém um advérbio, segundo o esquema $\mathrm{Adv}+\mathrm{di}$, como é o caso de lunju di, juntu di, bas di, dentru di, filadu di, fora di, lungu di, riba di e disna di. As que se formam com um nome enquadram-se no esquema $n a+\mathrm{N}+d i$. Nesse último caso, o que temos são as preposições $n a$ e di. A primeira delas ( $n a$ ) indica localização de algo no denotatum do nome, ao passo que a segunda $(d i)$ indica a que ou a quem esse denotatum pertence. Como vimos, a genitividade é uma das principais funções secundárias de $d i$, logo depois da função principal indicada na figura 06.

As "preposições complexas" que contêm um advérbio mais $d i$ apresentariam, pelo menos superficialmente, uma estrutura diferente $(\mathrm{Adv}+d i)$, como já vimos. No entanto, é sabido desde pelo menos a Grammaire générale et raisonneé (1830), de Arnauld e Lancelot, que os advérbios correspondem a uma preposição mais um nome. Assim, dizem eles, sapienter (sábio) equivale a cum sapientia (com sabedoria), hodie (hoje) corresponde a in hoc die (em este dia). Isso significa que o $l i$ crioulo (e seu correspondente português "aqui") corresponderia, pelo menos semanticamente, a in hoc loco (em este lugar). Com base nessas ideias, é perfeitamente legítimo considerar dentru di, por exemplo, como um equivalente de "no interior de". Se essa análise for válida, construções que aparentemente entrariam no esquema $A d v+d i$ têm, na verdade, a estrutura $n a+\mathrm{N}+d i$. Em suma, todas as preposições aparentemente complexas são, ao fim e ao cabo, frases que se iniciam pela preposição simples $n a$ e terminam pela preposição simples di. Isso explica porque di ocorre mais que na na estatística da Tabela 01. Em diversas construções, a ideia de localização indicada por $n a$ conflui com o nome seguinte. Plag (1998) discute casos semelhantes no sranan.

É bem verdade que essas construções são relativamente lexicalizadas, ao ponto de dentru di ser uma alternativa para o na prototípico. No entanto, existem outras construções desse tipo que não podem ser consideradas preposicionais. Um exemplo é na tempu di [fomi] (no tempo de [fome]). Tanto não se trata de uma locução prepositiva que há diversas outras construções similares, como na tempu di cuba (no tempo de chuva), na tempu di friu (no tempo que faz frio) etc. Inclusive com outros nomes há construções com a mesma estrutura, tais como na kau di Jon (no lugar de João), na kau di sinta (no lugar de sentar), na [tudu] kol- 
dadi di limaria (em todo tipo de animal). A forma na metadi di (entre) significa, literalmente, "no meio de".

Diversas outras construções sintáticas estão em paralelo com as que são examinadas. Por exemplo, kamalion pega na rabu di lubu (o camaleão agarrou no rabo do lobo), em que na rabu di é simplesmente parte de uma construção maior. O que acontece é que construções como na metadi di ocorrem com mais frequência do que ela. A maior frequência dá a impressão de que seria algo cristalizado como "pé-de-moleque", que formaria um todo indecomponível. Resumindo, o que temos nos casos presentes são as preposições $n a$ e $d i$. Em português temos construções similares, como "no âmago de", "no coração de". Não cremos que ocorreria a alguém considerar essas construções como locuções prepositivas.

\section{Preposições espaciais e o meio ambiente da língua}

Uma vez que as preposições têm sido consideradas tradicionalmente como desprovidas de significado extralinguístico, poderíamos ser levados a pensar que não têm nenhuma relação com o Meio Ambiente Natural da Língua. Na presente seção, nós gostaríamos de discutir este tópico mais pormenorizadamente. Com efeito, a maioria das preposições, se não todas, relacionam-se com o mundo físico, mesmo que indiretamente, pelo menos no momento de sua origem. Está implícito no texto de Sapir (1963) mencionado acima que apenas uma parte do léxico tem a ver com o mundo natural diretamente, ou seja, palavras de conteúdo. É o caso dos topônimos, antropônimos, nomes de espécimes da flora e da fauna, entre outros. Esses nomes referem-se a coisas de nosso meio ambiente imediato. Categorias funcionais como preposições não estariam no mesmo caso. No entanto, temos evidência de que, pelo menos de um ponto de vista genérico, também elas podem ser relacionadas com o mundo. De fato, as relações mostradas na figura 05 emergiram e foram armazenadas no cérebro dos membros da comunidade porque em tempos pretéritos as pessoas tinham contato direto com as coisas do mundo, que eram relacionadas umas com as outras de algum modo, por exemplo, como foi discutido na seção 04 .

A fim de evitar mal-entendidos sobre os diversos usos de um lexema de qualquer língua dada, é importante considerar o meio ambiente que ele designa para a coletividade. Isso se aplica não apenas a lexemas que designam "coisas", mas também àqueles que se referem às relações entre essas coisas. Seria insuficiente considerar apenas o contexto no qual o enunciado é proferido. Isso é o mesmo que dizer que não só as categorias lexicais podem ser relacionadas ao meio ambiente, mas também aspectos das palavras gramaticais e até mesmo da própria gramática, como sugerido por Heráclito e por Haiman (1980). Um forte argumen- 
to a favor desta relação inicial das preposições ao meio ambiente físico é o fato de frenti, por exemplo, provir do latim frons, frontis (face), via português. É provável que, em sua origem, tras (traseiro) tenha significado algo como "bunda". Em inglês, "back" significa a parte posterior do corpo, mas é também parte da locução prepositiva "in back of” (no traseiro de, atrás de). Construções crioulas como na ña dianti (na minha frente) e na ña tras (no meu traseiro) indicam que a locução preposicional tem um nome como cabeça, e esse substantivo é o nome de um lugar relativo do observador. De fato, o português tem a expressão "na minha frente", que é perfeitamente paralela a na ña dianti. Não há construção portuguesa paralela a na ña tras, talvez por tradição cultural. No entanto, podemos dizer "ele falou mal de mim nas minhas costas". Outra forma é "por trás", que tem um significado semelhante.

A lexicalização de expressões como as que acabam de ser vistas pode ter a ver com a sobrevivência de nossos ancestrais. Por exemplo, certamente era importante para os indivíduos saberem se o leão estava "no lado de seu traseiro" ou "no lado de sua cara". Do mesmo modo, era de vital importância saber se o leão estava "antes" ou "depois" de uma árvore, uma pequena colina ou um elefante. Se ele estava "antes", estava próximo do observador, uma situação perigosa. Do contrário, estaria longe dele, portanto, poderia cuidar de outros afazeres. Era importante para a pessoa em questão estar "dentro" ou "fora" da caverna. Mesmo que o leão não estivesse por perto, era importante estar "dentro" dela se estivesse chovendo, por exemplo. A preposição complexa na metadi di relaciona-se diretamente com o mundo físico. Ela indica um $\mathrm{C}$ localizado em um ponto "no meio de" ou "na metade" da linha que podia ser traçada entre A e B. Por sua vez, a riba e riba di (topo, em cima de) derivam do português "riba" que, por seu turno, provém do latim "ripa, ae" (margem, de um rio). A margem do rio, em geral, está em uma posição mais alta do que a da água corrente. No crioulo, "descer" é riba, isto é, originalmente, "vir para baixo". O equivalente desse tipo de relação em outras línguas pode ter a ver, mesmo que remotamente, com a cabeça, isto é, a parte superior da cabeça, ou o topo de montanhas ou de árvores.

O significado de $n a(\mathrm{em})$ e de seus equivalentes nas línguas europeias é totalmente opaco nos dias atuais. Entretanto, quando consideramos construções equivalentes como dentru di (mesmo significado), podemos especular que em priscas eras na pode ter provindo de algo significando "buraco" ou "caroço de uma fruta". Como vimos na Ecologia das Relações Espaciais, essa é a relação espacial mais primitiva, não-marcada. Em algumas línguas, o equivalente de na ainda é transparente. Em algumas línguas bantu, como luganda, a relação é indicada por um verbo significando algo como "estar-em". Em iorubá, a conjunção para "e" 
era, originalmente, “juntar-se”. Em amárico, essa função é indicada por um verbo que significa "repetir" (Gívón, 1979, p. 262-264). Nesse contexto, poderíamos incluir a serialização verbal em algumas línguas africanas e crioulas. De acordo com Bickerton (1981), sua existência nos crioulos é para suprir a paucidade de preposições, como pode ser visto no exemplo de (20), do são-tomense:

(20) E fa da ine ' $3 \mathrm{PS}_{1}$, falar, dar, $3 \mathrm{PS}_{2}$ ' ele $_{1}$ falou a ele, '

A tradução portuguesa encobre o significado real da sentença. Literalmente, ela assevera que alguém ( $\mathrm{E}$ 'ele ${ }_{1}$ ) falou e “deu” sua fala a outrem (ine 'ele ${ }_{2}$ '). Quer dizer, a função indicada pela preposição portuguesa "a" está sendo representada em são-tomense pelo verbo de movimento "da" (dar). Não é por acaso que o caso em questão seja o dativo. O fato de as línguas românicas não terem um lexema monomorfêmico para designar "à direita/esquerda de" é sugestiva da importância relativa que essa relação deve ter tido para a sobrevivência da espécie em seu meio ambiente. Nos nossos dados do crioulo, por exemplo, sequer essas locuções ocorreram. Se estritamente necessário, os falantes as tomam emprestadas do português. Algumas possibilidades seriam *na direita/iskerda di ou, então, na si ladu diritu (no seu lado direito) e na ladu di si mon diritu (no lado de sua mão direita). O que de fato ocorre com relativa frequência é na ladu di (ao lado de), independentemente de esquerda e direita.

Interessantemente, o tok pisin tem "apenas duas palavras que correspondem realmente a preposições portuguesas: long e bilong". A segunda "é usada para traduzir frases possessivas", como em has bilong papa (casa do meu pai), papa bilong mi (meu pai). No que tange a "long", é "usado sobretudo para relações espaciais entre objetos, bem como relações menos íntimas entre objetos do que as indicadas por long". Por exemplo, haus bilong bus (a casa no mato 'bush'), wok long gaten (trabalhar no jardim). "Para expressar localização precisa, "long" se compõe com nomes que indicam a localização desejada: antap long (no topo de, sobre), ananit long (embaixo de, sob), arare long (além de)" (cf. Laycock, 1970, p. xxviii). Um fato interessante no presente contexto é que o equivalente tok pisin para a preposição por excelência deriva do verbo inglês to belong (pertencer). Essa palavra é composta de be mais long, que é um adjetivo espacial. O fato é que na origem todas as preposições devem ter sido transparentes.

Como se pôde ver acima, a maioria das preposições crioulas são complexas, isto é, até certo ponto transparentes no sentido de Sapir ([1963] 2001). Ele observa que "quando uma expressão transparente é usada para um conceito simples, parece sensato concluir na maioria dos casos que o conhecimento do elemento do meio ambiente a que ela se refere é relativamente recente ou, pelo menos, que a designação teve lugar em data relativamente recente" (p. 16). No crioulo, há tam- 
bém a possibilidade de empréstimo recente do português. Sendo assim, apenas as formas da coluna esquerda da tabela 01 pertenceriam ao vocabulário tradicional da língua. Isso não exclui a possibilidade de que pelo menos algumas das preposições complexas da segunda coluna também possam ser antigas.

\section{Observações finais}

Nosso objetivo principal neste artigo foi relacionar as preposições ao Meio Ambiente Natural da Língua. Nesse sentido, vimos que as relações básicas são as indicadas na Ecologia das Relações Espaciais. No entanto, podemos afirmar que inclusive as não-básicas têm a ver com o esquema. Algumas delas são prototipicamente espaciais, ao passo que outras não. É claro que nem todo aspecto das preposições é considerado aqui. O que é mais, as próprias preposições espaciais cobrem um amplo espectro de áreas, como se pode ver em Vandeloise (1991) e Bennett (1975).

A preposição por excelência ( $n a$ ) é um bom exemplo. Imaginemos um observador no meio de um quarto. Nesse caso, na pode indicar todas as posições possíveis. Algo pode estar na tetu (no teto), na paredi (na parede) e na con (no chão). No caso, a parede pode ser a da frente, a de trás, a da direita ou a da esquerda do observador. É claro que o observador poderia usar também todas as preposições que codificam as relações espaciais específicas, ou seja, superioridade ("sobre", em vez de na tetu), inferioridade ("embaixo", em vez de na con) e assim por diante. Isso só confirma a relatividade das relações espaciais.

\section{Referências}

Arnault, Antoine \& Claude, Lancelot. Grammaire générale et raisonnée. Paris: Auguste Delalain. Republicada em 1969 por Republications Paulet, organizada por Michel Foucault, 1830.

Bärenfänger, Olaf. Merkmals- und Prototypensemantik: einige grundsätzliche Überlegungen. Linguistik v.12, n.3, p.2, 2005.

Bennett, David C. Spatial and temporal uses of english prepositions: an essay in stratificational semantics. Londres: Longman, 1975.

Borba, Francisco da Silva. Sistemas de preposições em português. São Paulo: Universidade de São Paulo, Tese de livre-docência inédita, 1971.

Bickerton, Derek. Roots of language. Ann Arbor: Karoma, 1981.

Bohm, David. A totalidade e a ordem implicada. 3.ed. São Paulo: Editora Cultrix, 2001.

Calvet, Louis-Jean. Pour une écologie des langues du monde. Paris: Plon, 1999.

Coleman, Linda \& Paul, Kay. Prototype semantics: The English word lie. Language v.57, n.1, p.26-44, 1981.

Couto, Hildo Honório do. Os conetivos. Universidade de São Paulo, M.A., diss. de Mestrado, 1973. 
Couto, Hildo Honório do. O crioulo português da Guiné-Bissau. Hamburgo: Helmut Buske Verlag, 1994.

Couto, Hildo Honório do. Ecolinguística: estudo das relações entre língua e meio ambiente. Brasília: Thesaurus, 2007.

Døør, Jørgen \& Jørgen, Chr. Bang. Language, ecology and truth - dialogue and dialectics. In: Fill, Alwin. (Org.) Sprachökologie und Ökolinguistik. Tübingen: Stauffenburg, 1996. p.17-25.

Eco, Umberto. A busca da língua perfeita. 2ed. São Paulo: Ed.Universidade Sagrado Coração, 2002.

Fill, Alwin. Ökolinguistik: Eine Einführung. Tübingen: Gunter Narr Verlag, 1993.

Fill, Alwin. (Org.) Sprachökologie und Ökolinguistik. Tübingen: Stauffenburg, 1996.

Fill, Alwin; Peter, Mühlhäusler (Org.) The ecolinguistics reader. Londres: Continuum, 2001.

Fill, Alwin; Hermine, Penz \& Wilhelm, Trampe (Org.) Colourful green ideas. Bern: Peter Lang, 2002.

França, Aniela Improta. Neurolinguística. Ciência hoje, v.36, n.21.p.20-25, $2005 .$.

Givón, Talmy. On understanding grammar. New York: Academic Press, 1979.

Greimas, A. J. Sémantique structurale. Paris: Librairie Larousse, 1966.

Hagege, Claude. L'homme de paroles. Paris: Fayard, 1985.

Haiman, John. The iconicity of grammar: isomorphism and motivation. Language v.56, n.3, p.515-540. 1980 .

Haugen, Einar. The ecology of language. The ecology of language. Stanford: Stanford University Press, 1972. p. 325-339.

Helbig, Gerhard. Geschichte der neueren Sprachwisseschaft. 2ed. Hamburg: Rowohlt, 1975.

Kihm, Alain. Kriyol syntax. Amsterdam: John Benjamins, 1994..

Lamb, Sydney M. Neuro-cognitive structure in the interplay of language and thought. In: Pütz, Martin; Marjolijn, H. Vespoor (Org.) Explorations in linguistic relativity. Amsterdam: Benjamins, 2000. p. 173-196.

Lang, Jürgen. Die französischen Präpositionen: funktion und bedeutung. Heidelberg: Carl Winter, 1991.

Laycock, Don. Material in New Guinea Pidgin (coastal and lowlands). Canberra: The Australian National University, 1970.

Lefebvre, Claire. Multifunctionality and variation among grammars: The case of determiner in Haitian and in Fongbe. Journal of pidgin and creole languages v.13, n.1., p.93-150, 1998.

Lyons, John. Semantics. vol.2, Cambridge: The University of Cambridge Press, 1977.

Mackey, William. Toward an ecology of language contact. In: Mackey \& Ornstein, J. (Org.) Sociolinguistic studies in language contact: methods and cases. Haia: Mouton, 1979. p.453-459.

Mackey, William.The ecology of language shift. In: Nelde, Peter (Org.) Sprachkontakt und Sprachkonflikt. Zeitschrift für dialektologie und linguistik Beiheft n. 32. Wiesbaden: Franz Steiner Verleg: 35-41, 1980. 
Makkai, Adam. Ecolinguistics: ¿Toward a new **paradigm** for the science of language? London: Pinter Publishers, 1993.

Mandelbaum, David (Org.) Selected writings of Edward Sapir in language, culture and personality. Berkeley: University of California Press, 1949. p. 89-103.

Mufwene, Salikoko. The ecology of language evolution. Cambridge: CUP, 2001.

Mühlhäusler, Peter. Language of environment :environment of language: a course in ecolinguistics. Londres: Battlebridge, 2003.

Naess, Arne. Heidegger, postmodern theory and deep ecology. The trumpeter v.14, n.4, 1997.

Odum, Eugene P. Fundamentals of ecology. 3. ed. Philadelphia: W. B. Saunders Company, 1971.

Ogden, C. K.; Richards, I. A. O significado de significado. Rio de Janeiro: Zahar Editores, 1972.

Peirce, Charles Sanders. 1972. Semiótica e filosofia. São Paulo: Editora Cultrix.

Plag, Ingo.The syntax of some locative expressions in Sranan: Preposition, postposition, or noun? Journal of pidgin and creole languages v.13, n.2. p.335-353, 1998.

Pottier, Bernard. Systématique des éléments de relation: étude de morphosyntaxe structurale romane. Paris: Librairie Klincksieck, 1962.

Pottier, Bernard. Grammaire de l'espagnol. Paris: Presse Universitaire de France, 1969.

Rosch, Eleanor. Cognitive representations of semantic categories. Journal of experimental psychology: General 104, n.3. p.192-233, 1975.

Salzinger, Kurt. Ecolinguistics: A radical behavior theory approach to language behavior. In: Doris Aaronson \& Robert W. Rieber (Org.) Psycholinguistic research: implications and applications. New York: Erlbaum, 1979. p. 109-129.

Sapir, Edward. Language and environment. Selected writings, p.89-103. Berkeley: University of California Press, 1963. (reproduzido em Fill \& Mühlhäusler 2001, p. 13-23; citou-se do último).

Schaff, Adam. Linguagem e conhecimento. Coimbra: Livraria Almedina, 1974.

Tansley, Arthur G. The use and abuse of vegetational concepts and terms. Ecology v.16, n.3.p.284-307, 1935.

Thompson, R. W. A note on some possible affinities between the creole dialects of the Old World and those of the New. Proceedings of the conference on creole language studies. Londres: MacMillan, 1961. p. 107-113.

Trampe, Wilhelm. Ökologische Linguistik. Opladen: Westdeutscher Verlag, 1990.

Vandeloise, Claude. Spatial prepositions: a case study from french. Chicago: The University of Chicago Press, 1991.

Wittgenstein, Ludwig. Tractatus logico-philosophicus. São Paulo: Ed.Nacional \& Ed.USP, 1968.

Zimmermann, Klaus. Ecología lingüística y planificación lingüística. In: Lluís, i Vidal Folch, Ariana \& Azucena, Palacios (Org.) Lenguas vivas en América Latina. Barcelona: Institut Català de Cooperació Iberoamericana, 2004, p. 93-109. 
Zimmermann, Klaus. Die Entstehung der Kreolsprachen: ein Versuch aus konstruktivistischer Sicht. In: Endruschat, Annette \& Axel Schönberger (Org.) Portugiesische Kreolsprachen: Entstehung, Entwicklung, Ausbau und Verwendung. Frankfurt/Main: Domus Editoria Europaea, p. 1144, 2005a.

Zimmermann, Klaus. Interferenz, Transferenz und Sprachmischung: Prolegomena zu einer konstruktivistischen Theorie des Sprachkontakts. In: Bidese, A. et al (Org.) Das Zimbrische zwischen Germanisch und Romanisch. Bochum: Brockmeyer, p. 3-23, $2005 \mathrm{~b}$. 